\title{
Life Cycle Assessment of a Smartphone
}

\author{
Mine Ercan, Jens Malmodin, Pernilla Bergmark \\ Ericsson Research, Ericsson AB \\ Stockholm, Sweden \\ mine.ercan@ericsson.com
}

\begin{abstract}
It is of interest to understand the life cycle contribution from the use of smartphones including their network usage, as well as to gain knowledge regarding the impact of the smartphone as a device to provide input for network studies. This cradle-to- grave study is based on life cycle assessment (LCA) methodology as outlined by the ISO14040 series and the supplementing ICT specific LCA standard from ETSI/ITU. The paper provides details regarding data collection, assumptions, methods and results. Furthermore, sensitivity analysis results for selected parameters are presented, including variations due to different secondary data sets. This study calculates the Global Warming Potential (GWP) for the assessed smartphone (a Sony Mobile $\mathrm{Z5}$ ) including accessories) to $57 \mathrm{~kg} \mathrm{CO}_{2} \mathrm{e}$ for an assumed operating life time of 3 years, excluding the network usage. Results are also presented for other impact categories and as yearly figures. In addition, the distribution of impacts between life cycle stages is provided for the assessed impact categories. Integrated circuit (IC) production is identified as a major contributor to the overall impacts followed by the production of the display. For GWP specifically, overall results are also provided including the network usage
\end{abstract}

Index Terms-ICT, GHG emissions, LCA, life cycle assessment, smartphone, telecommunication

\section{INTRODUCTION}

It is commonly known that the use of smartphones in mobile communication networks is rapidly growing worldwide and thereby their contribution to the environmental and economic impacts of telecommunication networks. Although our research forecasts that the Information and Communication Technology (ICT) sector to remain within $2 \%$ of the total global greenhouse gas (GHG) emissions until 2020 [1], such development indicates an increased need for information regarding the environmental effects of smartphones. Recently, initiatives to reduce the energy consumption and the GHG emissions of communication networks have gained momentum. There is also an increasing interest in resource efficiency and the circular economy [2], and in eco-rating of mobile phones [34]. Consequently life cycle impact assessments are needed for smartphones to build a comprehensive understanding of their potential environmental impacts.

In their literature review of mobile phone LCAs [5], Suckling and Lee note that most studies that assess the life cycle impacts of mobile phones (including smartphones but also feature phones), report impact only in terms of GWP or energy [6]. As noted by Moberg et al. [7], the global warming potential (GWP) category alone cannot be used to

\author{
Emma Kimfalk (former employee), Ellinor Nilsson \\ Sony Mobile Communications \\ Corporate Sustainability Office \\ Lund, Sweden \\ ellinor.nilsson@sonymobile.com
}

represent all environmental impacts and thus broader studies are needed to gain a comprehensive understanding of the environmental impacts of mobile phones, especially toxicity impacts (which on the other hand show large uncertainties as this study shows). Suckling and Lee [5] also note that the majority of studies are published by manufacturers and note several circumstances that make results hard to compare. The authors of this study agree with this view and make every effort to present results for a broad range of impact categories and a sufficient level of detail, in order for the results to be comprehensive and interpretable. However, due to its importance, and considered as the most important impact category by the ETSI/ITU standard, GWP is given a greater focus than other impact categories.

The paper outline is as follows: firstly the methodology is presented in section II, then the goal and scope in section III and the life cycle inventory (LCI) in section IV. In section V the results of the life cycle impact assessment (LCIA) are given followed by interpretation and normalization combined with a sensitivity analysis in section VI. The paper concludes with a discussion in section VII and conclusions are finally drawn in section VIII.

\section{METHODOLOGY}

This study is based on LCA methodology as outlined by ISO and covers a multiple number of impact categories of the smartphone and its associated network usage, from cradle-to-grave. Furthermore it considers the joint standard for LCA of ICT goods, networks and services developed by European Telecommunications Standard Institute (ETSI) [8] and International Telecommunication Union (ITU) [9].

In line with Ercan [6] and Moberg et al. [7], who suggest to prioritize primary data collection efforts on key components (primarily integrated circuits) and energy use during production and use stage, this study has used primary data for production processes to the extent possible and calculated results for three different usage scenarios as actual usage varies between users. Further data details are given in section IV.

GaBi software [10] has been used as the modeling tool for this study and as a source for secondary data, including the data sets from Eco-invent as well as GaBi's own data.

\section{SCOPE}

\section{A. Product system}

The study is targeting two new high-end smartphones by Sony (models Z3 and Z5) with accessories (see Fig. 1). It 
includes the smartphone device itself as well as, for GWP, the associated life cycle impact from the network usage. The main difference between Z3 and Z5 models is the total integrated (IC) chip area, where Z5 has a larger area (9.5 $\mathrm{cm}^{2}$ ) compared to Z3 $\left(7.5 \mathrm{~cm}^{2}\right)$. The touch-screens have the same size, and most other parts and components are the same; so the difference in weight is only a few grams.

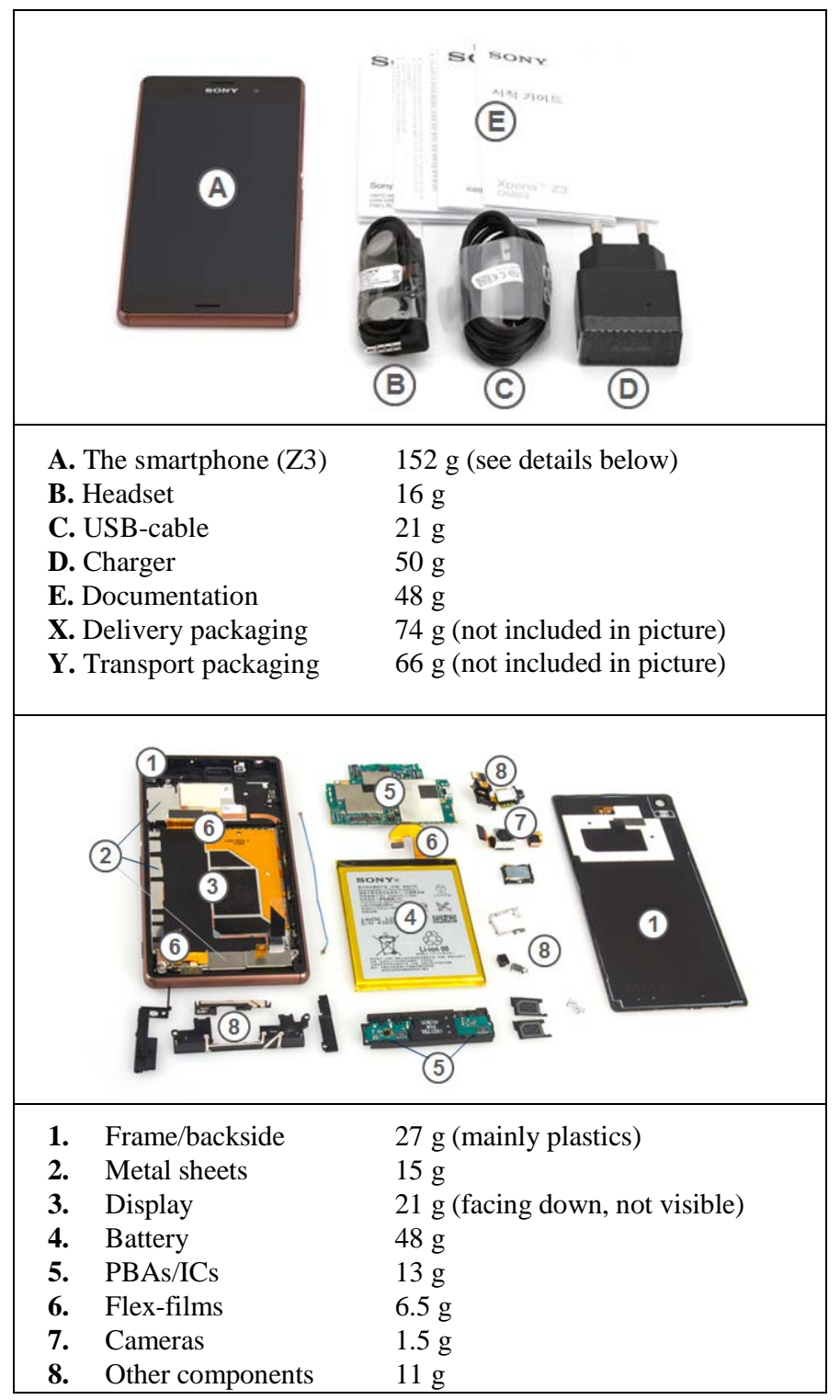

Fig. 1. Smartphone composition and accessories

Embodied impacts from software developed outside Sony (apps in general) are not included in the scope, however software impacts are considered for the use stage as data center services are included in network usage.

\section{B. Functional unit}

The functional unit is set to life time usage (3 years) of the smartphone device and its accessories for a representative usage scenario.
See section IV for specifications of the usage scenario.

For GWP, results are also presented per year and including the life cycle impact from the associated network usage.

\section{System boundaries}

All life cycle stages and processes are included in accordance with the joint ETSI/ITU LCA standard ([8]-[9]) except reconditioning of mobile phones for reuse. For a detailed overview of processes refer to Figure 7 of the standard. Two cut-offs were made: Impact from third party overhead activities (e.g. marketing services) were not included in the supporting activities. Impact from materials beyond the around 30 most contributing materials according to the previous experience of the authors were not accounted for.

\section{Impact indicators}

Based on recommendations from the International Reference Life Cycle Data System (ILCD) [11], the environmental life cycle impact assessment (ELCIA) indicators are chosen as presented in Table I together with the adopted impact assessment methods.

TABLE I. IMPACT INDICATORS

\begin{tabular}{|l|l|l|}
\hline $\begin{array}{l}\text { ELCIA indicators as } \\
\text { recommended by ILCD }\end{array}$ & Unit & Reference \\
\hline Global Warming Potential (GWP) & $\mathrm{CO}_{2}$-eq. & IPCC, 100 years \\
\hline Ozone Depletion Potential (ODP) & CFC-11-eq. & $\begin{array}{l}\text { WMO model, } \\
\text { ReCiPe }\end{array}$ \\
\hline $\begin{array}{l}\text { Human Toxicity Cancer potential } \\
\text { effects (HumToxCan) }\end{array}$ & CTUh & USEtox \\
\hline $\begin{array}{l}\text { Human Toxicity non-Cancer } \\
\text { potential effects (HumTox) }\end{array}$ & CTUh & USEtox \\
\hline Particulate Matter (2.5 $\mu$ m) (PM) & G & RiskPoll \\
\hline $\begin{array}{l}\text { Photo-Oxidant Creation Potential } \\
\text { (POCP) }\end{array}$ & NMVOC-eq. & $\begin{array}{l}\text { LOTOS-EUROS } \\
\text { model, ReCiPe }\end{array}$ \\
\hline Acidification Potential (AP) & $\begin{array}{l}\text { Mole of H - } \\
\text { eq. }\end{array}$ & $\begin{array}{l}\text { Accumulated } \\
\text { exceedance model }\end{array}$ \\
\hline $\begin{array}{l}\text { Eutrophication Potential (fresh } \\
\text { water) (EP fresh) }\end{array}$ & Mole of N-eq. & $\begin{array}{l}\text { EUTREND model, } \\
\text { ReCiPe }\end{array}$ \\
\hline $\begin{array}{l}\text { Eutrophication Potential (terrestrial) } \\
\text { (EP terr) }\end{array}$ & g P-eq. & $\begin{array}{l}\text { Accumulated } \\
\text { exceedance model }\end{array}$ \\
\hline $\begin{array}{l}\text { Eco-system Toxicity potential effects } \\
\text { (EcoTox) }\end{array}$ & CTUe & USEtox \\
\hline Freshwater consumption (Water) & m ${ }^{3}$ & Swiss Ecoscarcity \\
\hline Abiotic Depletion Potential (ADP) & Sb-eq. & $\begin{array}{l}\text { CML (reserve } \\
\text { based) }\end{array}$ \\
\hline
\end{tabular}

\section{LIFE CYCLE INVENTORY}

\section{A. Emission factors}

Generic GaBi models have been used for the energy and fuel models. The emission factors include the supply chain for the energy and fuel production, as it may have significant environmental impacts on the total results.

For primary data, the production related electricity mixes are based on the locations of the suppliers. For secondary $\mathrm{GaBi}$ data, electricity mixes are based on locations embodied 
in the data. For ICs and ASICs specifically, supplier information was used corresponding to an emission factor close to world average (around 0,6 kg/kWh).

For use stage, a world average emission factor was applied as the assessed products are intended for a global market.

As reflected in Section V and VI energy models were first modelled based on Ecoinvent data, then also with $\mathrm{GaBi}$ data. The Ecoinvent energy models include building construction and materials (including metals) within their system boundaries.

\section{B. Raw Materials Acquisition}

\section{1) Smartphone raw materials}

Primary materials data were provided by Sony per part presented in Fig. 1, and for selected components, such as printed board assemblies (PBAs). The component level data were used to model other similar components. For example, materials for all Application Specific Integrated Circuits (ASICs) were based on materials for one ASICs scaled up to reflect the overall ASIC weight. The acquisition processes for these raw materials were modeled in $\mathrm{GaBi}$ based on secondary data. Transportations related to the raw material acquisition stage were included in these data to an unknown extend and it was not possible to extract transportation details from the available data set. Electricity mixes are based on location and embodied in the GaBi data.

\section{2) Packaging materials}

Amounts of packaging materials for parts and final delivery have been estimated based on Ericsson conditions and factors have been applied that represent the packaging material weight in relation to the part or device weight. Some parts such as the IC and PBA require more packaging as they are more fragile and hence have a higher packaging factor.

Packaging materials include steel, polyurethane foam, polyurethane wood, plywood and cardboard and their acquisition processes are based on secondary $\mathrm{GaBi}$ data.

\section{3) Virgin and recycled materials}

The raw material stage takes into consideration the virgin and recycled inputs for some selected materials; copper, gold, silver and aluminium based on world market conditions. The virgin material input varies between 30 to 80 percent based on global recycling rates [12].

ETSI/ITU recommends a 50/50 approach to be used. This approach seeks to distribute the impacts from primary material production and waste treatment to the first and last life cycle in equal amounts, however without considering material loss at design or end-of-life treatment. Due to lack of details in the used data base, the 50/50 approach could not be applied consistently. For this reason this study developed an own approach by applying the 50/50 approach for two different scenarios for smartphone recycling (19\% or $83 \%$ depending on modelling of informal recycling) based on [13] and a world average rate of recycled gold ( $28 \%$ based on industry data from CPM group) For other metals, the $\mathrm{GaBi}$ models did not distinguish between virgin and recycled materials. For these metals the GaBi models were applied directly representing an unknown mix of virgin and recycled materials.

Li-battery recycling (e.g. cobalt) has not been included but the impact will be minor and mainly add to ADP.

\section{Production}

\section{1) Parts production}

Production process data are based on primary data collected from Sony's suppliers through a questionnaire where input was provided as annual figures for 2014 representing energy consumption, generated waste, ancillary products, emissions to soil, air and water and production related transportations. With the exception of ICs and ASICs, supplier support activities are excluded. Data were obtained from direct suppliers to Sony but not from the sub-suppliers. Table II below shows primary and secondary data sources for parts production. Where primary input data were insufficient or unavailable, data from previous studies or secondary data were used.

TABLE II: PARTS PRODUCTION DATA TYPES FOR THE SMARTPHONE

\begin{tabular}{|ll|l|}
\hline \multicolumn{2}{|l|}{ Primary supplier data } & Secondary data \\
\hline Charger & Vibrator & ASICS and IC (ICT \\
Headset & Camera & specific, see section C 2) \\
USB & Battery & Connectors (GaBi) \\
Packaging box & FCB & Inductor Chip (GaBi) \\
Sony assembly & Speaker & Resistors (GaBi) \\
Key Panel & Antenna & Capacitors (GaBi) \\
Touch and Display & PCB & \\
Microphone & RF Switch & \\
RF Switch & ASICS and IC (partly) & \\
\hline
\end{tabular}

The collected facility data were allocated based on Sony's share of overall production and surface area (ASICS, IC and PBA) or weight (all others).

Due to confidentiality, production related input data including location of facilities have restricted availability but the resulting potential environmental impacts are presented in section $\mathrm{V}$.

\section{2) Integrated circuit (IC) production}

The production of ICs is known as a resource intensive production process with substantial energy and resource use with among the highest environmental impacts per mass unit that exist today for mass produced products. The model used in this study considers yield and covers all main production processes including production of silicon wafer, chip on wafer ("wafer-fab") and the IC packaging (encapsulation). Also of main importance and included for the wafer fab, and to some extent also for other processes, are production of all special gases, chemicals and materials; emissions of gases with high GWP; supporting activities; and; the building of the factory itself and the production of process equipment.

For IC and ASICs the quality of the primary data collected from suppliers were found insufficient. Instead secondary $\mathrm{GaBi}$ data were used. However, the data for $\mathrm{CO}_{2}$ and some other critical GWP gases in the GaBi dataset were considered too low when compared to supplier data from 
earlier Ericsson LCAs including information from major suppliers like Intel, Texas Instruments, LSI, TSMC (used also by Texas and LSI) and former ST-Ericsson. Based on their input the total GHG emissions for production of ICs including life cycle impact of ancillary materials for smartphones are estimated to be in the range of $2.7-4.3 \mathrm{~kg}$ $\mathrm{CO}_{2} \mathrm{e}$ per $\mathrm{cm}^{2}$ of good die (total GHG emissions are only split on fully functional chip area, i.e. yield is considered).

The data show that the electricity consumption and emission of gases with high GWP in the wafer factory are two of the most important individual contributors, corresponding to an average electricity consumption for processors and ASIC's of about $3 \mathrm{kWh} / \mathrm{cm}^{2}$ and about 2 $\mathrm{kWh} / \mathrm{cm}^{2}$ for memories (yields included, i.e. allocated to fully functional chip area).

The average GWP for overall production impacts of all ICs for the assessed smartphone is about $3.5 \mathrm{~kg} \mathrm{CO} \mathrm{CO}_{2} \mathrm{e}$ per $\mathrm{cm}^{2}$ - somewhat higher for the processors and ASICs (about $4 \mathrm{~kg}$ ) and somewhat lower for the memories (about $3 \mathrm{~kg}$ ) as they consume less electricity per $\mathrm{cm}^{2}$ and have higher production yields than processors and ASICs.

To put these figures into perspective, early, unpublished Ericsson studies in the mid-90s showed wafer factory energy consumption for different IC types 3-10 $\mathrm{kWh} / \mathrm{cm}^{2}$ with yield included (or 2-4 $\mathrm{kWh} / \mathrm{cm}^{2}$ chip area without considering yield). Mobile phone ASICs were found in the upper part of this range. The electricity consumption of high end IC components today is comparable to that of low end components in 1995, and emissions of high-emitting GWP gases have been reduced from around 1-1.5 $\mathrm{kg} \mathrm{CO}_{2} \mathrm{e} / \mathrm{cm}^{2}$ down to about $0.5 \mathrm{~kg} \mathrm{CO} \mathrm{CO}_{2} \mathrm{e} / \mathrm{cm}^{2}$.

\section{3) Display production}

Another process that gained special attention during the study was the display production for which the authors had limited data regarding impact levels. Further, the display production could be expected to be an important contributor to overall impacts as it is known to require a very clean environment and substantial inputs of water, gases and chemicals.

According to the supplier, the electricity consumption in the display manufacturing is about $0.1 \mathrm{kWh} / \mathrm{cm}^{2}$ (including the touch layer). As for ICs the data shows that the impact from input of water, gases and chemicals and from supporting activities is large compared to other components.

The supplier data included information regarding the production process, as well as LCA results for another display type. Of these, the LCA results could not be used for materials to avoid double counting with the materials data acquired through materials declarations. Furthermore, the material content represented a display intended for a TV with different characteristics. However the LCA data was used to modify the factory energy data for GWP to include support activities. This could not be done for other impact categories. Combining the factory data and the LCA leads to higher uncertainty for the display than for other production processes, especially since no prior data was available for validation.

\section{4) Part Transportation}

Transportation types, weights and distances are obtained from the suppliers through the questionnaire. This includes inbound (both production and ancillary materials) and outbound (parts and waste) transports. The primary data is combined with models for the different means of transportation that are based on secondary data.

Packaging weights have been included in the transportation models.

\section{5) Assembly}

Final assembly of the smartphone is performed by Sony. Data for the assembly processes are primary data collected from a Sony assembly site and cover energy consumption, generated waste, ancillary products, emissions to soil, air and water and production related transportations.

6) ICT manufacturer support activities

ICT manufacturer support activities were estimated based on primary data regarding energy consumption for main offices and business travelling (not hotels) which were allocated to the device based on sales volumes. It was assumed that the need for supporting activities was the same for all products.

\section{7) Distribution}

Transportation types, weights and distances for distribution to retailers were built on internal Sony data. Based on the main transportation routes to all continents, a global average scenario was developed for air and road transportation of the final product. The primary distribution data were combined with secondary data for the models for the different means of transportation.

Packaging weight has been included in the transportation models but user travelling was not included.

\section{Use}

The use stage consists of usage of the device and associated usage of the mobile network infrastructure. A global energy mix has been adopted for the usage stage.

\section{1) Smartphone use}

The smartphone energy consumption is based on a reasonable usage scenario (described below) which is assumed to be the representative case, based on Sony data for charging time and energy consumption during charging and for chargers in stand-by.

Two other scenarios, assumed to represent heavy and light users, were developed for the sensitivity analysis. The user scenarios differ with respect to the battery charging cycles and lifetime. A representative user is considered to charge the device once every two days whereas the heavy and light users charge every day and every $3^{\text {rd }}$ day respectively, as shown in Table III. The phone energy consumption includes the daily power consumption of the device based on chargers and power consumption of battery while charging and in standby-mode power consumption. A charging time applicable to Z5 and Z3 conditions is embodied in the figures. It was also assumed that the representative user would change phone every 3 years, while 
the corresponding operating life time for the light and heavy users were set to 4 and 2 years respectively.

TABLE III. SMARTPHONE DEVICE ENERGY CONSUMPTION

\begin{tabular}{|c|c|c|c|}
\hline & $\begin{array}{c}\text { Heavy } \\
\text { User }\end{array}$ & $\begin{array}{c}\text { Representative } \\
\text { User }\end{array}$ & $\begin{array}{c}\text { Light } \\
\text { User }\end{array}$ \\
\hline Maximum charge cycle (days) & 1 & 2 & 3 \\
\hline $\begin{array}{c}\text { Phone Energy Consumption } \\
\text { (kWh/year)* }\end{array}$ & 7.74 & 3.87 & 2.58 \\
\hline Usage (years)* & 2 & 3 & 4 \\
\hline Source * Sony
\end{tabular}

Source: *Sony

2) Associated use of networks

For GWP, the user's use of the mobile networks was considered. For this impact category, the studied system hence included the wireless network which is needed in order to have a working mobile service. For the network related impact, data was adapted from [14] which give more detailed information on network data, assumptions and assessment method. Network related impacts included impacts from mobile networks (access and core) and data networks (data centers, data transmissions and IP core networks).

Table IV presents the mobile and wi-fi network usage for the different usage scenarios. Impacts considered include life cycle impact of the listed network products allocated to the smartphone based on [14]. More specifically, wi-fi and the traffic dependent network energy consumption were allocated based on traffic, while the static energy consumption of mobile networks was allocated based on number of subscribers. Also operator's supporting activities were included and allocated per subscriber.

TABLE IV. NETWORK USAGE FOR THE THREE USAGE SCENARIOS

\begin{tabular}{|c|c|c|c|}
\hline & Heavy User & $\begin{array}{c}\text { Representative } \\
\text { User }\end{array}$ & Light User \\
\hline $\begin{array}{c}\text { Mobile + wi-fi data } \\
\text { traffic }\end{array}$ & $\begin{array}{c}\text { 30GB**+ } \\
\text { 30GB* }\end{array}$ & $\begin{array}{c}11 G B * *+ \\
11 G B *\end{array}$ & $\begin{array}{c}\text { 5.5GB** + } \\
5.5 G^{*} *\end{array}$ \\
\hline \multicolumn{4}{|c|}{ Use of mobile networks per year* } \\
\hline $\begin{array}{c}\text { RBS 3G Operation } \\
\text { (kWh/subyear) }\end{array}$ & 25 & 22 & 21 \\
\hline $\begin{array}{c}\text { RBS Embodied } \\
\text { (kg CO} 2 \mathrm{e} / \text { subyear) }\end{array}$ & 3.5 & 3.5 & 3.5 \\
\hline $\begin{array}{c}\text { Operator, } \\
\text { transmission, data } \\
\text { centers } \\
\text { (kWh/subyear) }\end{array}$ & 15 & 8 & 6 \\
\hline $\begin{array}{c}\text { Operation services } \\
\text { (travel) } \\
\text { (kg CO } 2 \mathrm{e} / \text { subyear) }\end{array}$ & 2.6 & 2.6 & 2.6 \\
\hline $\begin{array}{c}\text { Other embodied } \\
\text { (kg CO } \mathrm{CO}_{2} \mathrm{e} / \text { subyear) }\end{array}$ & 0.7 & 0.7 & 0.7 \\
\hline \multicolumn{4}{|c|}{ Use of wi-fi per year** } \\
\hline $\begin{array}{l}\text { Wi-fi Operation } \\
\text { (kWh/subyear) }\end{array}$ & 9 & 3.3 & 1.65 \\
\hline $\begin{array}{c}\text { Wi-fi embodied } \\
\text { (kg CO } \mathrm{Kg}_{2} \mathrm{e} \text { subyear) }\end{array}$ & 0.9 & 0.3 & 0.15 \\
\hline
\end{tabular}

Source:*[14], **([15], [16])

The network data usage is representative for high end smartphones for Swedish mobile networks and data traffic in 2015. As Sweden, together with Finland, [17] has the highest data usage intensity in the world the data volumes may be too high in a global scenario, however, it provides a reference for the current state-of-the-art networks.

The Swedish GWP figures were adjusted to reflect a global electricity mix.

\section{E. End-of-Life Treatment}

End-of-life-treatment (EoLT) is modelled based on [13] which investigates regional and global waste flows in order to set up EoLT scenarios for ICT equipment. While noting the non-consistent data types and the substantial differences in quality between waste flow data for different countries, Liebmann [13] attempts to model regional waste flows. For the regional grouping, mobile phone subscription counts are used to weight each country's estimated percentage of generated waste. The model considers the percentage of waste generated within the region as well as import and export of waste. However, in some mainly importing regions no data were found for export flows.

Regional findings are aggregated to estimate a global end-oflife treatment scenario for ICT equipment, also based on the number of mobile phone subscriptions.

Informal recycling is found to be a major EoLT activity. Due to unavailable data and obvious modelling difficulties for informal recycling, this fraction was instead modelled as formal recycling resulting in an overall recycling rate of $83 \%$ vs $17 \%$ landfill based on weight. This approach should be seen as a best case, or a non-conservative scenario. A more conservative, yet not the worst-case, approach would be to model the informal recycling as landfill, resulting in a recycling rate of $19 \%$ vs $81 \%$ landfill.

The recycling process data is based on Boliden and Kuusakoski recycling sites and landfill processes are based on generic data from GaBi. Due to lack of specific data, transportations related to recycling are modelled based on Ericsson internal conditions for recycling.

\section{RESULTS}

\section{A. Total Global Warming Potential of the device}

Figure 2 shows the GWP of a Z5 smartphone device including accessories but excluding network usage, over its life time (3 years) for the representative scenario specified in Table III. The GWP results for the life cycle impact of smartphone model Z5 is $57 \mathrm{~kg} \mathrm{CO} \mathrm{C}_{2}$. For Z3 the GWP corresponds to $50 \mathrm{~kg} \mathrm{CO} \mathrm{CO}_{2} \mathrm{e}$. The corresponding annual impact is 19 and $17 \mathrm{~kg}$ respectively. Including also the network usage according to the representative scenario, the total impact figure increases by $43 \mathrm{~kg} \mathrm{CO}_{2} \mathrm{e}$ per year, or by a total of $129 \mathrm{~kg} \mathrm{CO}$ e per year. 


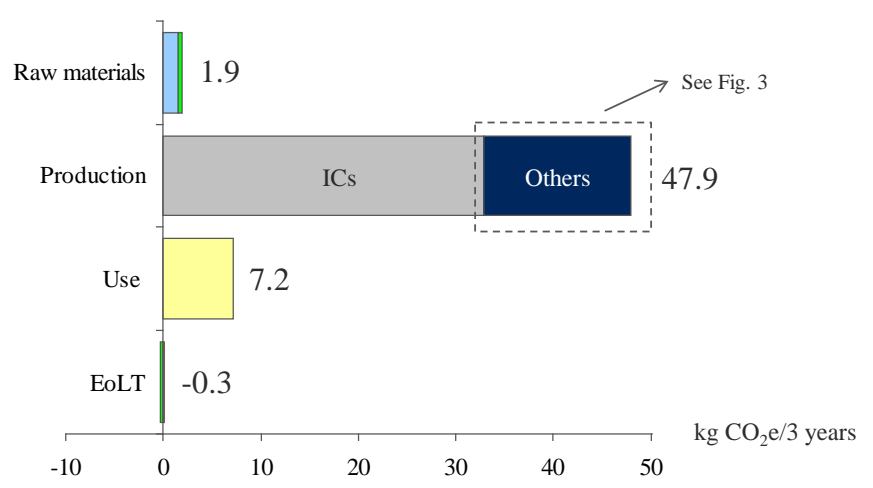

Fig.2 GWP for smartphone Z5 during its life time (3 years), including accessories but excluding network usage

Figure 2 shows that production, about $48 \mathrm{~kg} \mathrm{CO}_{2} \mathrm{e}$ in total for $\mathrm{Z} 5$ and dominated by IC production, contributes most to GWP for the $\mathrm{Z} 5$ device. The use stage gives about $7 \mathrm{~kg}$ $\mathrm{CO}_{2} \mathrm{e}$ in total for the $\mathrm{Z} 5$ and $\mathrm{Z3}$ models (corresponding to about $4 \mathrm{kWh}$ /year) over three years, assuming a global average electricity mix (0.6 kg CO $2 / \mathrm{kWh})$.

\section{B. GWP distribution within the production stage}

The total GHG emissions from IC production are about $33 \mathrm{~kg} \mathrm{CO}_{2} \mathrm{e}$ for the $\mathrm{Z} 5$ model and about $26 \mathrm{~kg}$ for $\mathrm{Z3}$ reflecting the difference in IC chip area $\left(9,5 \mathrm{vs} 7,5 \mathrm{~cm}^{2}\right)$.

For other production activities the GWP contributions are distributed according to figure 4 which shows that the second most important contributor is the display with a contribution of about $3.5 \mathrm{~kg} \mathrm{CO}_{2} \mathrm{e}$, as shown in Fig. 3.

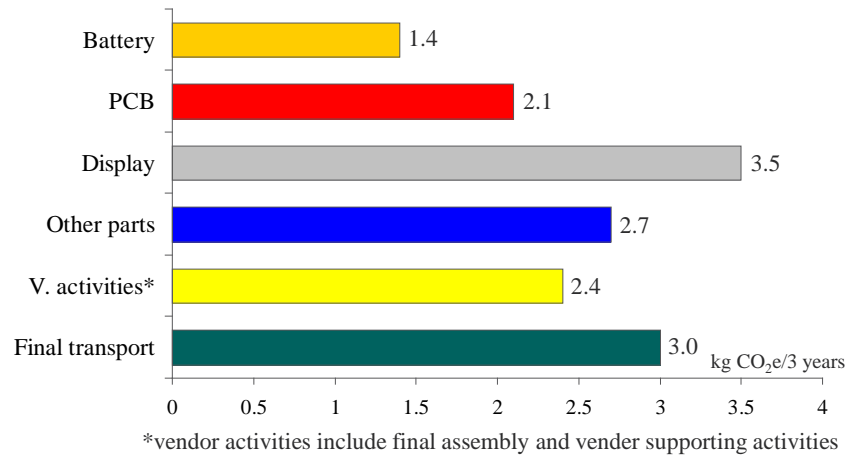

Fig. 3 Total GWP results for all production processes but IC for Z5

\section{Transport related GWP impacts}

Final transportation contributes to the total results (3 years) with $3 \mathrm{~kg}$ of $\mathrm{CO}_{2} \mathrm{e}$. Additionally, embedded in the production stage, production related transportations are included and account for $2.6 \mathrm{~kg} \mathrm{CO}_{2} \mathrm{e}$. The raw material acquisition stage and waste and EoLT related transportations are accounted for in the GaBi models but are not possible to separate from the models. These transportation impacts are assumed to be very small, below $0.1 \mathrm{~kg} \mathrm{CO}_{2} \mathrm{e}$. Thus total transportation is estimated to be $5.6 \mathrm{~kg} \mathrm{CO}_{2} \mathrm{e}$, i.e. around $10 \%$ of total impacts.

\section{Other impact categories}

The results for other impact categories are presented in Figure 4 and 5 for the Z5 smartphone including accessories but excluding network usage, over its life time (3 years) for the representative scenario specified in Table III.

Figure 4 shows the contribution from the raw material and EoLT, production and use stage for all impact categories based on eco-invent data for gold and energy production, while figure 5 is based on $\mathrm{GaBi}$ data for gold and energy production.

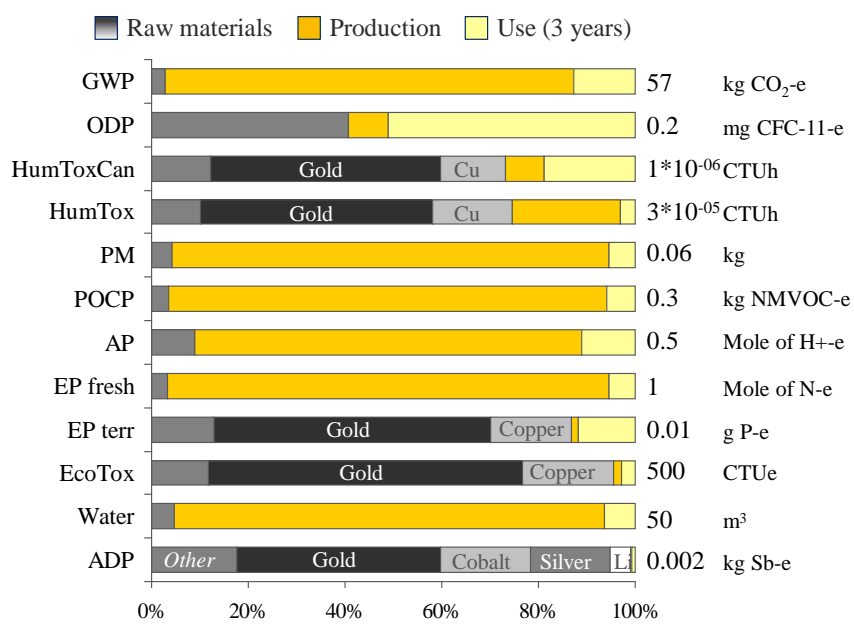

Fig. 4 Total life cycle result for all impact categories for smartphone Z5 with accessories using Ecoinvent database and adopting a 50/50 recycling approach with $19 \%$ recycling of gold assumed.

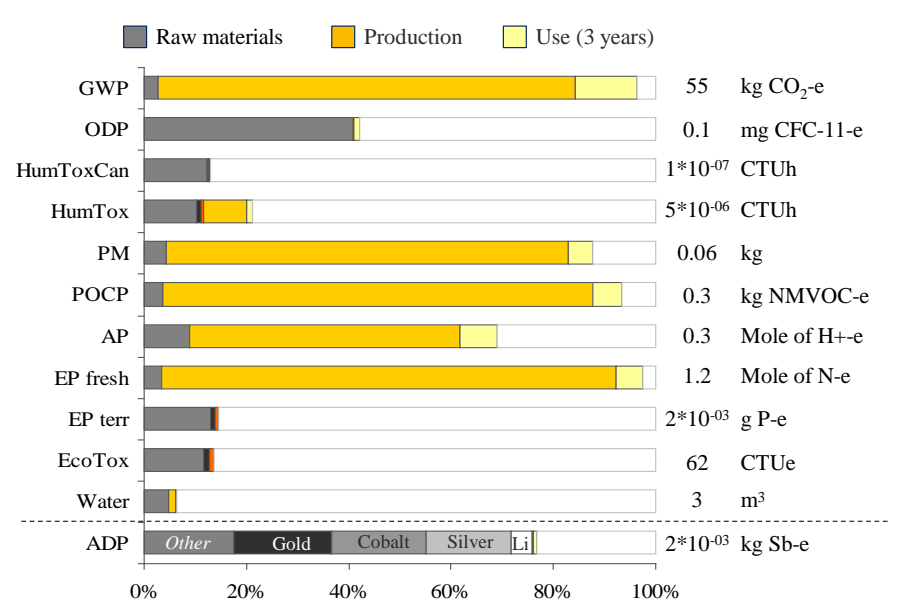

Fig. 5 Total life cycle result for all impact categories for smartphone Z5 with accessories using $\mathrm{GaBi}$ database for gold and energy production and a $50 / 50$ recycling approach with $83 \%$ recycling of gold assumed. Note that the figure shows relative results compared to figure 4

In figure 5, Ecoinvent gold and copper data and models are replaced by GaBi's own data models, and the results are expressed in percentage of the Ecoinvent based results indicating a large difference in results due to the two data sets. Neither of the two scenarios presented in Fig. 4 and 5 could be described as the true one, rather they represent a 
range of possible outcomes. See section V for further details. Also the recycling potential differs between Figure 4 and 5 . However this has only a minor impact on the result.

Both figure 4 and 5 indicate that the use stage is relatively small for all impact categories, except for Ozone depletion in the Ecoinvent case. For both data sets the production stage dominates the impacts for GWP, Particulate Matter, Photo-Oxidant Creation Potential, Acidification Potential and Eutrophication of fresh water. For the Ecoinvent data set also water is dominated by the production stage. The remaining categories are dominated by the raw materials acquisition.

\section{INTERPRETATION AND SENSITIVITY ANALYSIS}

The detailed results show that production and use impact comes to a high degree from electricity consumption, and raw material toxicity impacts are dominated by gold and copper mining. To understand the impact of parameter settings sensitivity analysis was made for life time, data traffic and gold production data. Due to time restrictions the sensitivity analysis has so far only been performed for these parameters.

\section{A. Impacts from gold modelling}

As identified by Moberg et al. [7], gold belongs to the prioritized data collection processes. In the present study, when applying the Ecoinvent data set, gold is contributing to nearly half of the abiotic resource depletion potential (also cobalt, silver and lithium give significant contributions). These results depend on the amount of gold that is needed to produce a smartphone, the rate of recycled gold that enters the smartphone life cycle, how the EoLT stage is modeled, and the gold recycling rate at EoL.

As emphasized in Figure 4 the toxic impact potential is dominated by the acquisition of gold, followed by the copper processes. This is due to the time boundaries applied for the Ecoinvent data set which covers an extremely long time frame compared to other data sets for mining tailings emissions (in the order of 10000 years), resulting in high toxicity impacts, especially related to gold and copper mining. Furthermore, the Ecoinvent models assumes leakage of metals based on the conditions of one mine in South America for which mining tailings and dams are assumed to constantly leak or even break. The Ecoinvent data model can thus be seen as a worst case scenario. The extensive time frame may be reasonable, but as other data sets take another perspective the time frame should be remembered when comparing studies.

In figure 5, Ecoinvent gold and copper data and models are replaced by GaBi's own data models, representing a modern Northern Europe mine and smelter.

Besides the contribution from Gold, Abiotic Resource Depletion Potential also gets significant contributions from Silver, Cobalt and Lithium. However, if the Ecoinvent model is replaced by the $\mathrm{GaBi}$ model representing a modern Northern Europe mine and smelter, the potential toxic impacts data reduces down do just a few percentage of the impacts found with the Ecoinvent - 1\% for HumToxCan, 4\% for HumTox and 4\% for EcoTox.

\section{B. Impact from the usage scenario}

The main usage scenario of this study is the representative scenario described in Table III and Table IV. To check the importance of this scenario, the light and heavy usage scenarios were established.The three scenarios differ with respect to lifetime (2-4 years) and data traffic (from 5,5 GB mobile+5,5 GB wi-fi to $30 \mathrm{~GB}$ mobile+30 GB wi-fi).

The smartphone network usage, based on the three cases, varies between 36, 43 and $67 \mathrm{~kg} \mathrm{CO}_{2} \mathrm{e}$ per year - to be compared to the yearly device impacts of $19 \mathrm{~kg} \mathrm{CO}_{2} \mathrm{e}$ making it clear that inclusion of the network significantly affect the results and thus require caution when comparing and communicating studies.
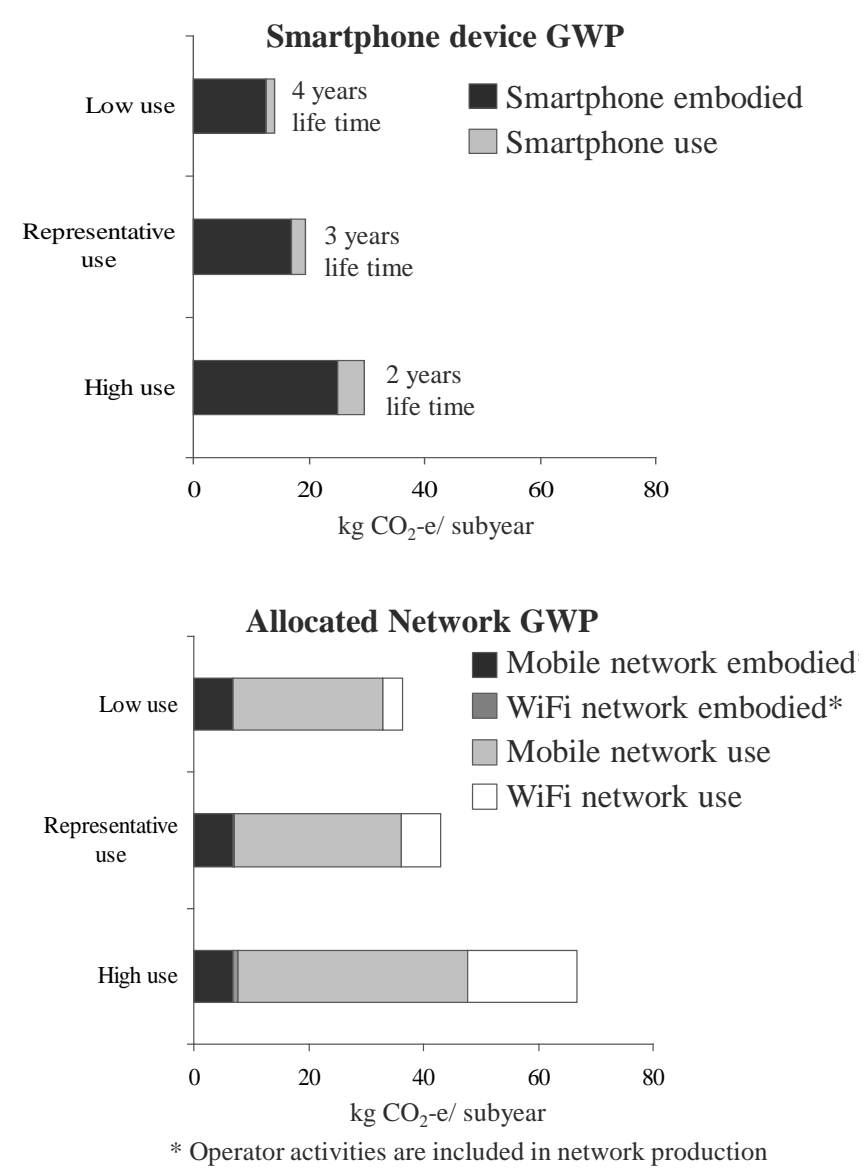

Figure 6 Sensitivity analysis of life time and data traffic

Figure 6 varies lifetime and data traffic simultanously which makes it difficult to tell their influence apart. When varying these parameters separately it turns out that the decvice usage impact is sensitive to life time, while the network usage varies with data usage.

\section{Normalization}

To put the results in perspective normalization was performed. The normalization represents the yearly Z5 smartphone life cycle impact (excluding the network usage) 
compared to the overall impact per person and year globally according to reference values from $\mathrm{GaBi}$, generally based on the LCIA source data The normalization was performed for the two data sets (Ecoinvent and $\mathrm{GaBi}$ ) and recycling conditions according to Figure 4 and 5, and Figure 7 demonstrates the substantial difference between the two.

Long-term toxicity effects (like those considered in the $\mathrm{GaBi}$ data) are not included in the reference values making the relative Ecoinvent percentages too high for toxicity.

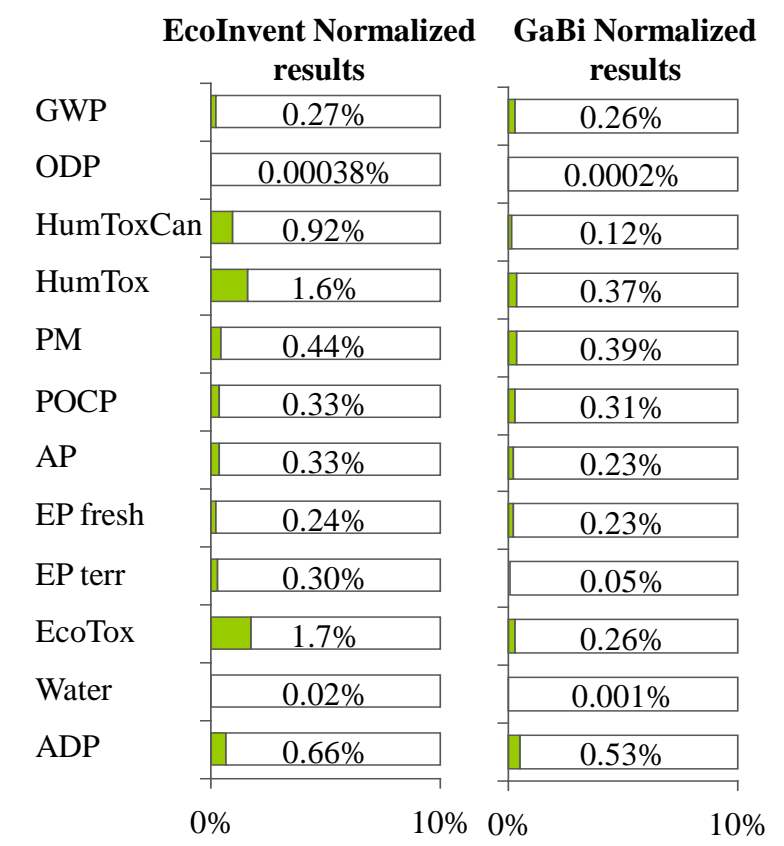

Figure 8 Yearly Z5 smartphone device life cycle impacts normalized based on overall yearly impact per person per category based on the representative scenario

\section{DISCUSSION}

\section{A. General}

As reflected in the ETSI/ITU standard, the life cycle assessment of an ICT product, in this case the smartphone is a very complex task. As the device has multiple parts, each with several suppliers dynamically shifting over time, the data collection is demanding and time intense and it is not possible to collect data from all suppliers. The geographical dispersion of the production sites, the differences in usage of the devices and networks operation as well as the production and maintenance of the network infrastructure and equipment is complex in terms of both scope and allocation.

The continuous development of technology, resulting in new products, limits the possibility to perform complete, up to date LCAs on all ICT equipment but makes it important to build understanding based on representative products to follow the development as technology advances.

\section{B. Standard compliance}

This study has had the ambition to comply with the joint ITU/ETSI standard ([8]-[9]). Compliance was achieved with the following exceptions:
- The materials model was limited to the about 30 most impacting materials.

- The 50/50 approach for allocation between life cycles could only be applied to gold.

- Transport data for raw materials, waste and EoLT could not be presented separately.

- Reporting formats were not followed due to limitations in number of pages.

- For the same reason, a full data quality and uncertainty description is missing, and the detailed calculations are not described.

- Results are not presented for electricity, primary energy and fuel usage, only for impacts.

- Embodied impacts due to software (including apps) developed by other parties than Sony was not considered. However, use of software is included in the overall usage scenarios.

- The sensitivity analysis was limited to few parameters.

\section{Comparison of GWP between studies - then and now}

Already in 1995, Ericsson (through the second author of this paper) performed an (unpublished) LCA of a mobile phone. Also that study identified ICs production and gold acquisition as main contributors. In that study the gold content was about $50 \mathrm{mg}$, compared to $20 \mathrm{mg}$ for the Sony Z5 targeted by this study. In contrast the chiparea was only $40 \%$ of the Z5 chip area. However, the energy consumption was higher and production yields lower in 1995, making ICs the most contributing components. The production of the Nickel-Cadmium batteries used in 1995 also had a higher environmental impact, including GWP, than today's Lithium batteries.

The most important LCA results from the early LCA studies of mobile phones were probably the insight that chargers, usually not unplugged after use, contributed substantially to the impact. This contribution increased as users could have several chargers plugged-in in parallell. This insight made the leading brands (Ericsson, NOKIA and Motorola) develop chargers that switched themselves off, reducing stand-by power from several Watts to below 0.5 Watt. An internal Ericsson LCA study in 2008 confirmed this trend and showed a stand-by power below 0.1 Watt and a charger left in stand-by all of the time resulted in less than $1 \mathrm{kWh} /$ year.It is estimated that the total emission savings for stand-by power reductions for mobile chargers was in the range of 100 million tonnes $\mathrm{CO}_{2} \mathrm{e}$.

The total GWP results for the production and use stages from this study are compared to the outcome of other recent and older LCA studies with similar scope and system boundaries, see Fig 8 .

Of recent studies, the generic smartphone study by Fairphone/Fraunhofer [18] and Apple's iPhone studies [19] reviewed and approved by Faunhofer were addressed in Fig. 8. For GWP, Fraunhofer shows about the same relative importance of the IC production and also get a similar result for the embodied emissions, about $50 \mathrm{~kg} \mathrm{CO} \mathrm{CO}_{2}$. For the use stage, however, they get a higher footprint, corresponding to 
about $15 \mathrm{~kg} \mathrm{CO}$ e over 3 years compared to $7 \mathrm{~kg}$ (for Z5) in our study for comparable emisssion factors.

The Fraunhofer and Apple study assumes much higher memory capacity which is likely to cause most of the higher footprints in those studies.

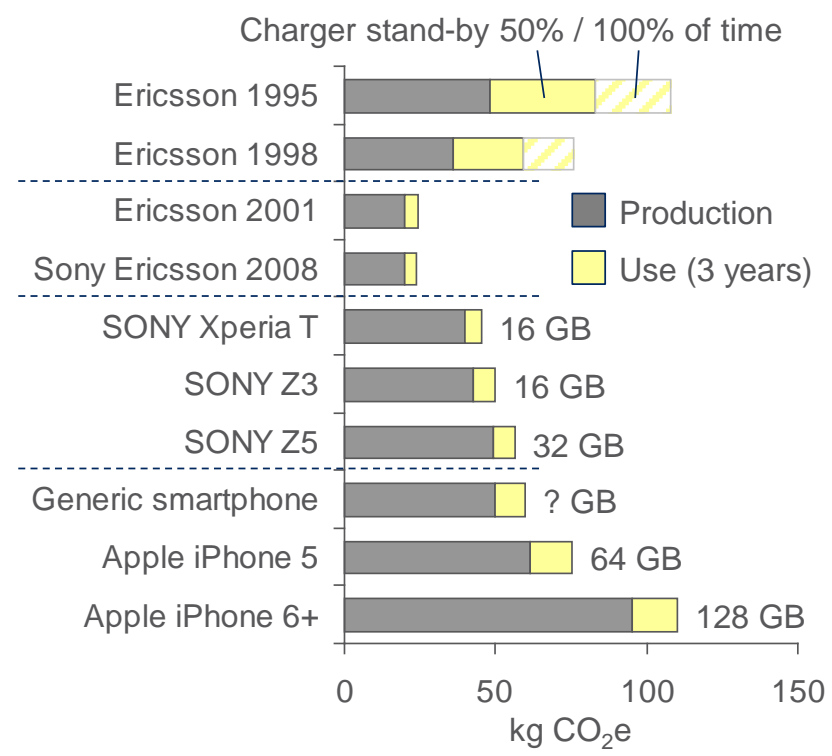

Fig 8 GWP results for different mobile LCA studies. Note that the figure cannot be used to make conclusion regarding the relative impacts of different smartphone models, just to compare study results.

\section{Use of LCA results for eco-rating}

Sustainability and environmental concerns are increasingly gaining a global significance. To move in a sustainable direction, human behavior needs to change as well [20]. For this reason, many industry sectors have developed ways to provide product related sustainability information to customers, with the aim to positively influence their habits and purchasing decisions. This development is also visible in the mobile industry where multiple eco-rating schemes are established to communicate product related information to customers, sometimes considering also embodied impacts.

Direct comparison of different LCA results can be misleading if differences in methodology, assumptions, system boundaries etc. are not considered. Additionally, mobile devices vary in performance and features and it may be challenging to find a good way to balance their footprints towards their indirect effects. On a more positive note there seem to be an opportunity in using LCA results to identify hotspots to address and could also be used as the foundation for improving supply chain performance and company performance in order to make them more sustainable. As an example LCAs could identify materials and processes with high impacts. LCAs could also be used to show how customer behavior affects the impacts. See figure6.

\section{E. The smartphone footprint vs its indirect effect}

Beyond the basic communication service for speech and data, smartphones also work as music and media players, radios, TVs, GPSs, cameras, video cameras, game consoles, alarm clocks, etc. Consequently, it seems reasonable when considering smartphone footprint to also consider how these features changes usage patterns for other consumer electronics. Sales figures for 2010, 2014 and 2015 for some of these devices are declining globally. Although the growth can still be high in developing countries, see Table V.

TABLE V GLOBAL SALES OF SOME CONSUMER DEVICES

\begin{tabular}{|l|c|c|c|}
\hline Global shipments [millions] & 2010 & 2014 & 2015 \\
\hline Game consoles & 78 & 47 & na \\
\hline Portable media players & 120 & 50 & na \\
\hline Digital cameras & 120 & 40 & na \\
\hline TVs & 250 & 220 & na \\
\hline PCs & 350 & 310 & 280 \\
\hline Tablets & 20 & 230 & 330 \\
\hline Smartphones & 305 & 1300 & 1400 \\
\hline
\end{tabular}

Sources: CEA, IDC, Gartner (na: not available)

Another interesting point is the total energy consumption of all consumer electronics in use in the US, which is now decreasing with a reduction of about 12\% between 2010 and 2013. The main reason for the reduction is less PCs and TVs in operation, and lower usage of these as media is accessed via smartphones and tablets. This is a trend break according to the US study which was conducted also in 2001 and 2006, see [21] for totals for all years.

The above statistics imply that it is reasonable to put the smartphone footprint into the perspective of the savings induced by their additional features. Additionally, not dealt with here, smartphones enable the use of ICT throughout society which could have the potential to substantially reduce overall societal GHG emissions as discussed in [22].

\section{CONCLUSIONS}

- $\quad$ The cradle-to-grave Global Warming Potential of the Z5 smartphone was estimated to $57 \mathrm{~kg} \mathrm{CO}_{2} \mathrm{e}$, including accessories but excluding network usage, representing its life time (3 years) impact for a Representative usage scenario. The corresponding annual impact was $19 \mathrm{~kg}$ $\mathrm{CO}_{2} \mathrm{e}$ without network, and $62 \mathrm{~kg} \mathrm{CO}_{2} \mathrm{e}$ with network usage included

- The major part of the GHG emissions, $48 \mathrm{~kg} \mathrm{CO}_{2} \mathrm{e}$, was related to the production processes where the IC production dominated. The use stage resulted in $7 \mathrm{~kg}$ $\mathrm{CO}_{2} \mathrm{e}$ for the smartphone itself (battery charging with a global average electricity mix).

- The use stage was relatively small for all impact categories. The production stage dominates the impacts for GWP, Particulate Matter, Photo-Oxidant Creation Potential, Acidification Potential and Fresh water Eutrophication. The remaining categories are dominated by the raw materials acquisition

- Most GWP but also most particulate matter, photooxidant creation and acidification potentials are related to the fossil fuel share of the electricity consumption.

- Gold and copper are the main contributors to the toxic impact categories and resource depletion (together with 
battery metals) but their contribution is highly dependent on the data source. The study uses two scenarios to show the large variation in data for mining of rare metals.

- For the use stage, the device usage impact is sensitive to life time, while the network usage varies with data usage.

- EoLT models have high uncertainty due to a profound lack of data.

\section{ACKNOWLEDGMENTS}

The authors would like to thank the Center for Sustainable Communications (CESC) at KTH Royal Institute of Technology in Sweden, for continuous discussions and knowledge sharing on ICT for sustainability and LCA.

\section{REFERENCES}

[1] The future carbon footprint of ICT and E\&M sectors, 2013, ICT4S Proceedings DOI Available online: http://dx.doi.org/10.3929/ethz-a-007337628 (accessed on 15 April 2016)

[2] Europe 2020, 20?? A resource-efficient Europe - Flagship initiative of the Europe 2020 Strategy Available online: http://ec.europa.eu/resource-efficient-europe/ (accessed on 15 April 2016)

[3] ITU, 2012. Review of mobile handset eco-rating schemes. Available online: https://www.itu.int/dms_pub/itut/oth/4B/01/T4B010000030001PDFE.pdf (accessed on 15 April 2016)

[4] ITU 2016. Ongoing work at ITU: Question 16/5 Leveraging and enhancing the ICT environmental sustainability. Available online: http://www.itu.int/en/ITUT/studygroups/2013-2016/05/Pages/q16.aspx (accessed on 15 April 2016)

[5] Suckling, J., Lee,J., 2015. Redefining scope: the true environmental impact of smartphones, Int J Life Cycle Assessments 20:1181-1196 DOI 10.1007/s11367-0150909-

[6] Ercan, M. 2013 Global warming potential of a Smartphone; using life cycle assessment methodology. Available online: http://kth.divaportal.org/smash/get/diva2:677729/FULLTEXT01.pdf (accessed on 5 February 2016)

[7] Moberg, $\AA$ et.al. 2014. Simplifying a life cycle assessment of a mobile phone. International Journal of Life Cycle Assessment. volume 19, issue 5, pp. 979 - 993

[8] European Telecommunications Standards Institute. ETSI ES 203199 V1.3.1 (2015-02): Environmental Engineering (EE); Methodology for environmental Life Cycle Assessment (LCA) of Information and Communication Technology (ICT) goods, networks and services Available online: http://www.etsi.org/deliver/etsi_es/203100_203199/203199 /01.03.01_60/es_203199v010301p.pdf (accessed on 2 February 2016).

[9] International Telecommunication Union. ITU L.1410 (2014-12): Methodology for environmental Life Cycle Assessment (LCA) of Information and Communication Technology (ICT) goods, networks and services Available online: https://www.itu.int/rec/T-REC-L.1410-201412-I/en (accessed on 2 February 2016).
[10] GaBi LCA software. [computer program] Available online: http://www.gabi-software.com/sweden/index/ (accessed on 2 February 2016).

[11] European Platform on Life Cycle Assessment http://eplca.jrc.ec.europa.eu (accessed on 1 april 2016)

[12] UNEP 2011, Recycling rates of metals- A status report. Available online: http://www.unep.org/resourcepanel/Portals/24102/PDFs/M etals_Recycling_Rates_110412-1.pdf (accessed on 2 February 2016).

[13] Liebmann, A., 2015 ICT Waste Handling: Regional and Global End-of-Life Treatment Scenarios for ICT Equipment Royal Institute of Technology

[14] Malmodin, J., Lundén, D., Nilsson, M., Andersson. 2012. LCA of data transmission and IP core networks. Available online:http://www.ericsson.com/res/docs/2013/lca-of-datatransmission-and-ip-core-networks.pdf (accessed on 15 April 2016)

[15] Cisco Visual Networking Index: Global Mobile Data Traffic Forecast Update, 2015-2020 White Paper Available online:

http://www.cisco.com/c/en/us/solutions/collateral/serviceprovider/visual-networking-index-vni/mobile-white-paperc11-520862.html (accessed on 2 February 2016).

[16] Ericsson mobility report, 2015. On the pulse of the networked society Available online: http://www.ericsson.com/res/docs/2015/mobilityreport/ericsson-mobility-report-nov-2015.pdf (accessed on 15 April 2016)

[17] Tefficient AB, 2015. Mobile data usage- Price and bucket size matter Available online: http://media.tefficient.com/2015/06/tefficient-industryanalysis-2-2015-mobile-data-usage-and-pricing-26June.pdf (accessed on 15 April 2016)

[18] Fairphone (Faunhofer), 2013. Available online: https://www.fairphone.com/2013/08/01/whats-in-a-lifecycle-assessment/ (accessed on 15 April 2016)

[19] Apple Inc. 2015. Environmental responsibility- Product reports Available online: http://www.apple.com/environment/reports/ (accessed on 4 April 2016).

[20] Urban, B. et. al. 2014. Energy consumption of consumer electronics in U.S. homes in 2013. Final report to the consumer electronics association (CEA). Fraunhofer USA center for sustainable energy systems. June 2014.

[21] Electronics Association. 2016. Rateko. Consumer Electronics Technical and Commercial Organizations. Journal with 6 issues every year including sale statistics. In cooperation with the Mobile Phones Association. Available online: www.rateko.se (accessed on January 2016)

[22] The future carbon footprint of ICT and E\&M sectors, 2013, ICT4S Proceedings DOI Available online: http://dx.doi.org/10.3929/ethz-a-007337628 (accessed on 15 April 2016) 